\title{
5. Challenging the assumptions supporting work experience as a pathway to employment
}

\section{Paula McDonald, Andrew Stewart and Damian Oliver}

\subsection{INTRODUCTION}

Taken at face value, there is a plausible link between work experience, employability and employment. We take work experience for this purpose to mean a period of time spent in a workplace to develop skills, contacts or familiarity with the requirements of a job, industry or profession. Employability, which is defined as 'the perceived ability to attain sustainable employment appropriate to one's qualification level' and which is often measured via student satisfaction surveys, is distinct from independent measures of employment outcomes. ${ }^{1}$ In relation to both potential outcomes, if work experience has emerged as a de facto prerequisite for securing professional employment in particular, those who do not participate will inevitably be at a disadvantage. These claims, however, rest on two key assumptions that constitute the focus of this chapter. The first is that it is possible, merely by participating in work experience, to acquire a competitive advantage over job-seeking peers who do not participate. This can only be logically true if participation is not universal and there are no effective substitutes. The second assumption is that, where participation is not universal, it does improve employability and enhance employment outcomes. In this chapter we challenge both of these assumptions, exposing the tensions inherent in research and policy on unpaid work experience through a synthesis of extant research. We do this by, first, problematizing the notion of competition and advantage in the labour market, especially in fields where the majority of graduates have completed a sustained period of work-integrated

1 Andrew Rothwell, Ian Herbert and Frances Rothwell, 'Self-Perceived Employability: Construction and Initial Validation of a Scale for University Students' (2008) 73 J Vocat Behav 1, 2. 
learning (WIL) during their degree or some other form of internship. Secondly, we present the available evidence on the relationship between employability/ employment outcomes and participation in work experience. Furthermore, to the extent that employability and employment outcomes can be enhanced, the question of access becomes crucial. We therefore examine the evidence for advantages that work experience may confer.

Our focus in this chapter is primarily, though not exclusively, on unpaid work experience. Although work experience can sometimes be paid, it is unpaid work experience which has attracted the most concern, as it is prominent in media revelations of exploitative practices, especially where young people undertake 'real' work for the primary benefit of the employer instead of acquiring authentic learning outcomes for themselves. Although unpaid work experience may be undertaken for a range of reasons, we focus here on participation directed towards acquiring professional or career employment, either during or following a degree programme. This includes compulsory, educationally focused work experience required by licensing or registration bodies or professional associations, such as in nursing or social work; ${ }^{2}$ voluntary, educationally focused work experience, which may be associated with less oversight by higher education institutions; and internships organized through the open market entirely outside an educational framework. Students may participate in any or all of these forms of unpaid work during or following a degree programme.

The chapter draws on a range of published studies to inform our claims, offering a critical and comprehensive synopsis of the available evidence that challenges some of the espoused benefits of these practices. It is important to note, however, that studies often do not explicitly distinguish between different forms of work experience or WIL, whether it is a compulsory or voluntary component of a degree, or internships organized on the open market. Where relevant, we use the term adopted in the source study. Finally, since unpaid work experience has become an entrenched feature of the youth employment landscape, the chapter concludes by discussing policy responses that may assist in ameliorating adverse impacts on participants.

\subsection{THE GROWTH OF UNPAID WORK EXPERIENCE}

A key assumption of proponents of unpaid work experience is that individuals who have greater opportunities to participate are conferred a competitive

2 Georgina Atkinson, Work-Based Learning and Work-Integrated Learning: Fostering Engagement with Employers (National Centre for Vocational Education Research 2016). 
advantage in the labour market over peers who have less opportunity to participate. Universities and vocational training institutions have contributed to the growth of unpaid work experience through significantly expanding WIL into a range of disciplines and fields of study where there are no statutory or professional requirements for work placement hours. This has been motivated by the apparent desire to provide their graduates with skills and knowledge they cannot acquire in the formal classroom and, therefore, a labour market advantage. ${ }^{3}$

There is some support for this assertion. For example, Roberts reported that nearly half of British employers believed that job candidates who have not gained work experience will have little or no chance of receiving a job offer for their organizations' graduate programmes, regardless of academic qualifications. ${ }^{4}$ Further, a study of pathways into employment in the Midlands region, based on interviews with young people and employers, found that work experience prior to entry to paid work is a strong prerequisite for all but the lowest skilled, lowest paid jobs. ${ }^{5}$ The perceived benefit of internships for graduates' employability is both absolute (acquiring skills they cannot develop in formal education or in non-career paid employment) and relative (accruing additional skills, experience and networks in excess of those required to perform a standard entry-level graduate role). Accordingly, students and graduates often rationalize their decisions to participate in unpaid work experience in complex, class-conscious, politicized ways that emphasize the delivery of desirable social and cultural capital in order to position themselves ahead of their peers. ${ }^{6}$ However, the expansion of unpaid work experience into a majority graduate experience raises the vexed question of how graduates can realistically differentiate themselves from their peers.

Abundant small-scale studies, as well as some emerging larger-scale research, suggest that unpaid interns represent 'a uniquely vulnerable, growing

3 Janice Orrell, Good Practice Report: Work-Integrated Learning (Australian Learning and Teaching Council 2011), https://tr.edu.au/resources/GPR_Work _Integrated_Learning_Orrell_2011.pdf, accessed 30 March 2021; Deborah Burke and Robert Carton, 'The Pedagogical, Legal and Ethical Implications of Unpaid Internships' (2013) 30 J Leg Stud Educ 99.

4 Carys Roberts, The Inbetweeners: The New Role of Internships in the Graduate Labour Market (Institute for Public Policy Research 2017).

$5 \quad$ Kate Purcell, Peter Elias, Anne Green, Gaby Atfield, Arlene Robertson, Noel Whiteside and others, Present Tense, Future Imperfect? Young People's Pathways into Work (Institute for Employment Research 2017), https://warwick.ac.uk/fac/soc/ier/ research/pathways/presenttensefutureimperfect_final.pdf, accessed 30 March 2021.

6 Pauline Leonard, Susan Halford and Katie Bruce, “"The New Degree?" Constructing Internships in the Third Sector' (2016) 50 Sociology 383. 
sector of the workforce'. ${ }^{7}$ Estimates of the increasing prevalence of internships include, for example, that around half of all US college students report having completed an internship, half of which are unpaid; that interns constitute approximately 1.3 per cent of the US labour force; and that creative graduates in particular may be prepared to work up to 1000 hours for free in order to increase their visibility in the industry. ${ }^{8}$ A European study conducted across 27 countries revealed that 46 per cent of survey respondents aged 18-35 years had participated in at least one traineeship, of which more than half were unpaid. ${ }^{9}$ United Kingdom-based Graduate Prospects reported that 45 per cent of the 22000 graduates they surveyed now secure entry-level jobs via internships, while in Canada, 42 per cent of university students reported having undertaken an institutionally organized work placement. ${ }^{10}$ A prevalence study of unpaid work experience undertaken in Australia suggests even higher estimates. More than half (58 per cent) of respondents aged 18-29 years had participated in at least one episode of unpaid work experience in the previous five years. ${ }^{11}$ Around half of participants' most recent experiences were associated with formal education or training (university, vocational education or secondary school).

The research above highlights that the advantage conferred by unpaid work experience is increasingly scaled. As participation becomes a central dimension of tertiary study, previous differentiation benefits are potentially erased. To distinguish themselves from their peers, in a process described by Brown and Hesketh as seeking 'entry into the winner's enclosure', young people may seek multiple episodes of work experience, for longer periods, or in higher status or internationally recognized organizations. ${ }^{12}$ It is not difficult to see how tensions may arise between the desire to acquire relevant workplace

7 Laura Fredericksen, 'Falling through the Cracks of Title VII: The Plight of the Unpaid Intern' (2013) 21 Geo Mason L Rev 245, 253.

8 Ross Perlin, Intern Nation: How to Earn Nothing and Learn Little in the Brave New Economy (Verso 2011); Sabina Siebert and Fiona Wilson, 'All Work and No Pay: Consequences of Unpaid Work in the Creative Industries' (2013) 27 Work, Empl \& Soc 711; Anthony P Carnevale and Andrew Hanson, 'Learn \& Earn: Career Pathways for Youth in the 21st Century' (2015) 4 EJICLS 76.

9 TNS Political \& Social, The Experience of Traineeships in the EU (Flash Eurobarometer 378, European Commission 2013), http://ec.europa.eu/commfrontoffice/ publicopinion/flash/fl_378_en.pdf, accessed 30 March 2021.

10 Miriam Kramer and Alex Usher, Work-Integrated Learning and Career-Ready Students: Examining the Evidence (Higher Education Strategy Associates 2011).

11 Damian Oliver, Paula McDonald, Andrew Stewart and Anne Hewitt, Unpaid

Work Experience in Australia: Prevalence, Nature and Impact (Department of Employment 2016).

${ }_{12}$ Phillip Brown and Anthony Hesketh, The Mismanagement of Talent: Employability and Jobs in the Knowledge Economy (OUP 2004) 2. 
exposure though internships and a grudging awareness of potential and actual exploitation. ${ }^{13}$ More broadly, critics have suggested the expansion of unpaid work experience can have the unintended effect of positioning the practice as an obligatory rite of passage to paid employment, ${ }^{14}$ and of placing downward pressure on the wages and opportunities of other workers. ${ }^{15}$ Hence, as regards our first assumption, as work experience becomes ubiquitous, both through requirements for professional registration and through normative practice, the competitive advantage conferred through participation may be diminished.

\subsection{INTERNSHIPS, EMPLOYABILITY AND EMPLOYMENT}

The primary justification for extending access to unpaid work experience is that it enhances employability, through increased skills, knowledge, experience and pre-professional identity, and by assisting individuals to match their human capital profile to labour market demands. ${ }^{16}$ Participation also allows individuals to establish connections with prospective employers and signpost their value, such as by allowing graduates to demonstrate their real-world experience in a 'try before you buy' culture. ${ }^{17}$ Graduate employability can be defined as 'the perceived ability to attain sustainable employment appropriate to one's qualification level'. ${ }^{18}$ Tholen differentiates mainstream notions of employability often seen in higher education and government policy, which emphasize strategic investments by autonomous individuals in education, training and skill acquisition, from critical framings of employability which emphasize that the construct is contextual, relational and structured by opportunities, inequalities and power relations. ${ }^{19}$

Most support in the literature for the claim that work experience improves labour market prospects rests on self-reported perceptions from the participants

13 Deanna Grant-Smith and Paula McDonald, 'Ubiquitous Yet Ambiguous: An Integrative Review of Unpaid Work' (2018) 20 IJMR 559.

14 Thomas A Discenna, 'The Discourses of Free Labour: Career Management, Employability, and the Unpaid Intern' (2016) 80 West J Commun 435.

15 Siebert and Wilson (n 8).

16 Sally Smith, Colin Smith and Martha Caddell, 'Can Pay, Should Pay? Exploring Employer and Student Perceptions of Paid and Unpaid Placements' (2015) 16 Active Learning High Educ 149; Discenna (n 14).

17 Vicki Smith, 'Enhancing Employability: Human, Cultural, and Social Capital in an Era of Turbulent Unpredictability' (2010) 63 Hum Rel 279; Siebert and Wilson (n $8)$.

18 Rothwell and others (n 1) 2.

19 Gerbrand Tholen, 'What Can Research into Graduate Employability Tell Us About Agency and Structure?’ (2015) 36 Br J Sociol Educ 766. 
themselves. This despite the fact that an individual can clearly be 'employable but unemployed'.${ }^{20}$ Evidence for the benefits of open-market internships which are not linked to an educational course is particularly lacking. ${ }^{21}$

Those who promote work experience as a viable conduit to graduate employment often rely on studies demonstrating student satisfaction with their experiences; that is, again, a subjective measure of employability, rather than employment outcomes per se. Students generally report positive outcomes of work-based experiences, considering them a future-orientated 'braggable investment', ${ }^{22}$ an essential strategy for gaining a competitive edge in the graduate marketplace, ${ }^{23}$ and an experience that improves their critical and analytical thinking in areas related to their study. ${ }^{24}$ The Australian prevalence study reported, for example, that 80 per cent of university students agreed or strongly agreed that their unpaid work experience had helped them develop new skills. ${ }^{25}$ A review of 57 peer-reviewed studies of the impact of internships identified a variety of student-defined benefits, including the enhancement of job and social skills, assistance in deciding on career paths, and improved employment outcomes in a career-orientated job following graduation. ${ }^{26}$

The employability benefits attributed to work experience are often associated with a number of caveats. Benefits depend on: the quality of mentoring provided to the intern and the nature of the tasks undertaken $;{ }^{27}$ opportunities to appraise and reflect on their experiences through learning activities and assessment ${ }^{28}$ the degree to which exploitative practices occur, such as unreasonable workloads, unethical tasks and risky physical activities, ${ }^{29}$ and the disciplinary field of the participant. ${ }^{30}$

20 Brown and Hesketh (n 12) 217.

21 Grant-Smith and McDonald (n 13).

22 Thomas Corrigan, 'Media and Cultural Industries Internships: A Thematic Review and Digital Labour Parallels' (2015) 13 tripleC 336, 341.

23 Andrew J Cannon and Mark J Arnold, 'Student Expectations of Collegiate Internship Programs in Business: A 10-Year Update' (1998) 73 J Educ Bus 202.

24 Kramer and Usher (n 10).

25 Oliver and others (n 11).

26 Gisela Sanahuja Vélez and Gabriela Ribes Giner, 'Effects of Business Internships on Students, Employers, and Higher Education Institutions: A Systematic Review' (2015) 52 J Employ Couns 121.

27 Ibid.

28 Susan M Matthew, Rosanne M Taylor and Robert A Ellis, 'Relationships Between Students' Experiences of Learning in an Undergraduate Internship Programme and New Graduates' Experiences of Professional Practice' (2012) 64 High Educ 529.

29 Perlin (n 8).

30 Alan Milburn, Unleashing Aspiration: Final Report of the Panel on Fair Access to the Professions (Stationery Office 2009). 
Open-market internships, in contrast to those that are aligned with a course of study, appear to attract greater quality concerns. Creative industries and media graduates are thought to be at particular risk of exploitation given their job motivations and the competitiveness of the sector. ${ }^{31}$ However, it cannot be assumed that, simply because work experience involves an educational provider, employability benefits will inevitably result. Although the potential for the exploitation of interns has been widely acknowledged, this is often framed as an inevitable trade-off for gaining employability benefits. Considering the perceived value of internships, it is unsurprising that interns will sometimes accept very poor conditions while also espousing positive sentiments about their experiences. ${ }^{32}$ Hence, regardless of their genesis, all work placements should focus on facilitating meaningful learning opportunities and skill development, since it is through the development of authentic work-based skills, knowledge and experience that employability benefits are most likely to be achieved.

In contrast to research addressing the impact of work experience on employability, econometric analysis of the extent to which participation improves employment outcomes is relatively scarce. ${ }^{33}$ There is also the added difficulty of directly comparing studies owing to differences in target sample (secondary, tertiary or vocational students) and how focal constructs (for example, WIL, paid, unpaid or open-market internships) are defined and measured. Outcome variables, such as full- or part-time employment (at differing skill levels) also vary across studies, as do time frames between completion of work experience and the measurement of outcomes.

Polidano and Tabasso examined data from the Longitudinal Survey of Australian Youth and found a positive relationship between combined, short-term structured workplace learning and classroom-based vocational education and training (VET), and subsequent full-time employment for upper

31 Will Hunt, Linda Ball and Emma Pollard, Crafting Futures: A Study of the Early Career of Crafts Graduates from UK Higher Education Institutions (Institute for Employment Studies, University of the Arts London and Crafts Council 2010); Kim Allen and Sumi Hollingworth, "Sticky Subjects" or "Cosmopolitan Creatives"? Social Class, Place and Urban Young People's Aspirations for Work in the Knowledge Economy' (2013) 50 Urban Stud 499.

32 Elaine Swan, 'The Internship Class: Subjectivity and Inequalities - Gender, Race and Class' in Adelina Broadbridge and Sandra Fielden (eds), Handbook of Gendered Careers in Management: Getting In, Getting On, Getting Out (Edward Elgar 2015).

33 Patricia Silva, Betina Lopes, Marco Costa, Ana I. Melo, Gonçalo Paiva Dias, Elisabeth Brito and others, 'The Million-Dollar Question: Can Internships Boost Employment?' (2018) 43 Studies High Educ 2. 
secondary students. ${ }^{34}$ Similarly positive associations between educationally focused internships and labour market outcomes and/or wages have been found in Finland, ${ }^{35}$ Denmark, ${ }^{36}$ and Spain and Italy. ${ }^{37}$ An indicator of the importance of high-quality placements on employment outcomes was found in the European study of traineeships mentioned previously. Those who participated in the 30 per cent of traineeships found to be inferior in quality were significantly less likely to find subsequent employment. ${ }^{38}$ To the extent that a paid internship may be considered a marker of quality, O'Higgins and Pinedo conclude, based on an analysis of data from the 2013 European survey, together with an online survey undertaken in 2015 by the Fair Internship Initiative, that paid internships are associated with better labour market outcomes than are unpaid internships, though there is little to suggest that the amount of the payment makes a significant difference. ${ }^{39} \mathrm{O}^{\text {'Higgins and Pinedo }}$ suggest a number of explanations for this finding, including that interns who are paid may be more motivated to invest significant effort into developing competencies through the internship, may be able to focus in a more directed way on their internship as they are not burdened by financial hardship, and have access to better training opportunities because companies use the internships as trial recruitment periods. ${ }^{40}$

The Australian prevalence study found that only 27 per cent of unpaid work participants were offered employment by the organization which had hosted their most recent placement. ${ }^{41}$ Further, respondents who had participated in open-market internships that were potentially unlawful (defined as involving the same work as that done by regular employees and which did not predominantly involve observing or performing mock or simulated tasks), were more

34 Cain Polidano and Domenico Tabasso, 'Making it Real: The Benefits of Workplace Learning in Upper-Secondary VET Courses' (2013) Melbourne Institute Working Paper 31/13, https://melbourneinstitute.unimelb.edu.au/publications/working -papers/search/result?paper=2156478, accessed 30 March 2021.

35 Iida Häkkinen, 'Working While Enrolled in a University: Does It Pay?' (2006) 13 Labour Econ 167.

36 Juanna Schrøter Joensen, 'Academic and Labour Market Success: The Impact of Student Employment, Abilities and Preferences' (SSRN, 2009), https://papers.ssrn .com/sol3/papers.cfm?abstract_id=1352077, accessed 30 March 2021.

37 Giampiero Passaretta and Moris Triventi, 'Work Experience during Higher Education and Post-Graduation Occupational Outcomes: A Comparative Study on Four European Countries' (2015) 56 Int J Comp Sociol 232.

38 TNS Political \& Social (n 9).

39 Niall O'Higgins and Luis Pinedo, 'Interns and Outcomes: Just How Effective are Internships as a Bridge to Stable Employment?' (2018) ILO Employment Policy Department Working Paper No 241.

40 Ibid. See also Chapter 3 in this volume.

41 Oliver and others (n 11). 
likely than their peers who had completed apparently lawful internships to be neither employed nor looking for work at the time the survey was completed. ${ }^{42}$ A recent study in the UK further suggested that university graduates who participate in an unpaid internship following the completion of their degree earn less 3.5 years after graduation than peers who go immediately into paid work or on to further study. ${ }^{43}$ Regarding mandatory unpaid work experience as part of active labour market programmes, research suggests that there is either no positive effect on employment outcomes or a reduced likelihood of separating from unemployment payments. ${ }^{44}$

In contrast to self-reported measures of the employability benefits of unpaid work experience (discussed further below), the studies cited previously offer only limited evidence of how unpaid internships affect objective employment outcomes. The dearth of literature on this subject may be partly due to the relative recency of the phenomena and/or the challenges associated with collecting representative data. Establishing causal relationships between internships and employment outcomes is also difficult owing to lagged effects (benefits may only accrue to participants over time) and/or the difficulty of establishing employment outcomes between comparable groups who have and have not participated, especially when the practice is widespread..$^{45}$ What is clear, however, is that while there is consistent evidence for employability benefits ensuing from work experience, especially if it is educationally focused, there is only tenuous and incomplete support for the assumption that work experience - whether educationally focused or not - delivers real employment benefits. That is, the proliferation of participation in work experience, widely offered by organizations, promoted and facilitated by governments, universities and other education institutions, and enthusiastically adopted by students and graduates, rests primarily on the assumption of labour market advantage, rather than on its empirical reality.

42 Andrew Stewart, Damian Oliver, Paula McDonald and Anne Hewitt, 'The Nature and Prevalence of Unlawful Unpaid Work Experience in Australia' (2018) 31 Aust J Labour L 157.

43 Angus Holford, 'Access to and Returns from Unpaid Graduate Internships' (2017) ISER Working Paper Series 07/2017, https://www.iser.essex.ac.uk/research/ publications/524563, accessed 30 March 2021.

44 James J Heckmann, Robert J LaLonde and Jeffrey A Smith, 'The Economics and Econometrics of Active Labor Market Programs' in Orley Ashenfelter and David Card (eds), Handbook of Labour Economics, vol 3A (Elsevier 1999); Jeff Borland and Yi-Ping Tseng, 'Does "Work for the Dole" Work? An Australian Perspective on Work Experience Programs' (2011) 43 Appl Econ 4353.

45 O'Higgins and Pinedo (n 39). 


\subsection{EQUITY AND ACCESS}

The significant expansion of unpaid work experience among university students and graduates seeking a professional career has raised concerns about equity of access, especially in relation to high-status, high-paying jobs, such as in finance, law and journalism. Policy solutions put forward to address this issue have been dualistic. The UK government has indicated a willingness to ban or at least limit unpaid internships owing to their potential impact on social mobility, ${ }^{46}$ although there has been no move yet to introduce this reform. In contrast, a UK report by Roberts, which examined the role of internships in the career paths of graduates and other skilled young people, argued for 'universities, employers and the government [to] act together to increase the overall availability of internships and minimise any barriers to take up for those who are disadvantaged' ${ }^{47}$ Similarly, higher education institutions around the world have made significant efforts to provide greater opportunities for students to access on-the-job work experience connected to specific courses and degrees. The National Work Integrated Learning Strategy in Australia, for example, promotes increased support for WIL on the basis that it enables students to develop employability skills and gain genuine work experience linked to their career objectives. ${ }^{48}$

United Kingdom-based bodies such as the Panel on Fair Access to the Professions, ${ }^{49}$ the Sutton Trust ${ }^{50}$ and the Social Mobility and Child Poverty Commission $^{51}$ have highlighted that professions, such as law, politics, journalism and finance, are dominated by individuals from privileged backgrounds. This has been attributed in part to wealthy families being able to afford to

46 Rowena Mason, 'Ban on Unpaid Internships Being Considered, Says UK Employment Minister' Guardian (London, 31 October 2016), https://www.theguardian .com/politics/2016/oct/30/unpaid-internships-face-ban-damian-hinds-uk-employment -minister, accessed 30 March 2021; UK Government, Good Work: A Response to the Taylor Review of Modern Working Practices (HM Government 2018), https:// www.gov.uk/government/publications/government-response-to-the-taylor-review-of -modern-working-practices, accessed 30 March 2021.

47 Roberts (n 4) 3 (emphasis added).

48 National WIL Partners, National Strategy on Work Integrated Learning in University Education (Universities Australia 2015), http://cdn1.acen.edu.au/wp -content/uploads/2015/03/National-WIL-Strategy-in-university-education-032015.pdf, accessed 30 March 2021.

49 Milburn (n 30).

50 Sutton Trust, 'Research Brief: Internship or Indenture?' (2014) Sutton Trust Research Brief 2/2014, https://www.suttontrust.com/wp-content/uploads/2020/01/ Unpaid-Internships-1.pdf, accessed 30 March 2021.

51 Social Mobility and Child Poverty Commission, State of the Nation 2014: Social Mobility and Child Poverty in Great Britain (HMSO 2014). 
support their children undertaking work experience in high-cost cities and having strong existing networks in desirable or high-status organizations. In contrast, disadvantaged graduates are generally less likely to possess the classand place-based habitus that enables them to see competitive opportunities as an option. ${ }^{52}$ Drawing on focus groups with a small number of interns, Roberts reported that young people from less privileged backgrounds can struggle to secure an internship owing to discrimination and low confidence in navigating opaque recruitment practices. ${ }^{53}$ Social class can therefore stamp an imprint on the role of internships in the transition from education to employment, extending and, even, intensifying the mechanisms of socio-economic reproduction already evident in the education system. ${ }^{54}$

Although the problem of equity of access is often asserted in relation to privately organized or advertised internships, it can also apply to WIL programmes administered by higher education institutions. This is because students from lower socio-economic backgrounds may struggle to afford the costs of travel and accommodation, especially if the host employer is at a distant location, or may face challenges in undertaking paid work to cover living expenses while concurrently participating in unpaid WIL. These limits to participation may therefore constrain career opportunities and access to particular employment pathways for those without adequate financial, social and education resources. ${ }^{55}$

Hunt and Scott compared access to paid internships with access to unpaid internships in a survey of creative arts graduates from the UK. ${ }^{56}$ The data showed that those from less advantaged backgrounds were less likely to participate in internships in general. However, after controlling for factors such as grades, institutional reputation and prior placement experience, it was paid internships the graduates found most difficult to secure. Hunt and Scott argued that their results undermine the myth of meritocracy, as factors other than academic ability and credentials play a significant part in employment opportunities and outcomes.

52 Allen and Hollingworth (n 31).

53 Roberts (n 4).

54 Wil Hunt and Peter Scott, 'Participation in Paid and Unpaid Internships Among Creative and Communications Graduates: Does Class Advantage Play a Part?' in Richard Waller, Nicola Ingram and Michael RM Ward (eds), Higher Education and Social Inequalities: University Admissions, Experiences, and Outcomes (Routledge 2017).

55 Alexandre Frenette, 'Making the Intern Economy: Role and Career Challenges of the Music Industry Intern' (2013) 40 Work \& Occupations 364.

56 Hunt and Scott (n 54). 
A social-class effect of participation in internships was also reported by Holford, who found that graduates who had completed unpaid internships had lower earnings than peers who had gone immediately into paid work or further study. ${ }^{57}$ He noted that this salary penalty is significantly mitigated for graduates with professional parents, arguing that their social and financial capital provides an advantage in accessing 'good' internships that allow opportunities to capitalize on experience in the labour market.

\subsection{POLICY CHALLENGES}

The increasing emphasis placed on real-world and relevant work exposure and experience by governments, employers, universities and students/graduates is, at least in part, a response to the problem of youth employment and contracting labour market opportunities for young people. In this chapter we have examined and challenged two related assumptions underpinning the expansion of internships and other forms of unpaid work: that is, competitive advantage over peers, and positive employability and employment outcomes. The evidence outlined suggests only tenuous support for each of these assumptions.

First, the expansion of unpaid work experience, in the numbers of individuals participating as well as the types of previously unaffected fields of study involved, means that individuals with even extensive workplace exposure are less likely to stand out from their peers than in the past. There is no evidence that the expansion of work experience has directly created new paid jobs, so graduates must compete with their peers for a limited number of career positions.

Second, definitive empirical evidence of the extent to which, or under what conditions, participation in unpaid work experience leads to jobs remains elusive. This stands in contrast to more substantial evidence of unpaid work enhancing capacities associated with employability, as reported by graduates themselves. As we have indicated, although research addressing these questions is likely to be plagued by methodological challenges, it is nonetheless critical. Many students clearly enjoy their intern experiences and perceive them to be of value in enhancing employability. Yet the sheer volume of anecdotal and empirical evidence of unequal access, exploitative practices, and the challenges faced by young people in simultaneously juggling paid work, study obligations and/or unpaid work, demands that these questions should be answered. Indeed, critics have argued that the characterization of unpaid work as 'not working but learning' is used to 'legitimately deny a whole raft of rights, protections and claims to wages and working conditions that are granted

\footnotetext{
57 Holford (n 43).
} 
to other workers' ${ }^{58}$ If unpaid work experience has become a compulsory rite of passage to paid employment, ${ }^{59}$ we at least need to know if the investment of individuals and institutions is worthwhile.

Emerging evidence suggests that paid, rather than unpaid, internships tend to be of higher quality and may facilitate better quality learning experiences and more successful employment outcomes. ${ }^{60}$ If work experience improves participants' employability and/or significantly increases the likelihood of obtaining paid employment in the graduate labour market, we should be vigilant that social background does not limit access or play a part in sorting individuals into high- and low-quality internships. Paying work experience participants does not solve the problem of unequal access, but policy responses should still encourage a greater proportion of work experience episodes to be paid, at least at the minimum adult wage.

The practice of work experience - whether paid or unpaid - is now an entrenched feature of youth education-to-work transitions in many countries. Critical media commentary and the efforts of specialized advocacy groups, such as Intern Aware in the UK, the Geneva Interns Association, the Canadian Intern Association and Interns Australia, may help to curb some of the excesses identified. However, host organizations play a vital gatekeeping role in deciding who has access, and are key to shaping the quality of participants' learning experiences. Although employers have, to date, been reluctant to engage with broader critiques of unpaid work, their practices may be moderated through effective state regulation. This might involve, among other things, placing limits on the length of internships and taking action against businesses that systematically use interns as a free source of labour. ${ }^{61}$

It is difficult to imagine a time in the foreseeable future where unpaid work experience will be completely banned, or even considerably scaled back. A recent comparative study of the regulation of internships reveals that a few countries, such as Argentina, Brazil and France, have legislated to prohibit open-market internships, requiring unpaid work to be undertaken only in conjunction with an educational institution, and then only subject to various regulatory requirements. Other nations, such as Germany, while not going so far, have endeavoured to extend labour protections to open-market interns, even if they might not otherwise be regarded as employees in the ordinary sense. More commonly, however, the legal status of these arrangements is unclear.

58 Mayssoun Sukarieh and Stuart Tannock, 'The Education Penalty: School, Learning and the Diminishing of Wages, Working Conditions and Worker Power' (2015) 38 Br J Sociol Educ 245, 249.

59 Discenna (n 14).

60 O'Higgins and Pinedo (n 39).

${ }_{61}$ Stewart and others (n 42). See also Chapter 20 in this volume. 
In countries such as the USA, the UK and Australia, it has been necessary to bring test cases to determine whether interns qualify for minimum wages or other entitlements; and, in the first two of those countries at least, those cases have not always succeeded. It is also common for both educationally focused and open-market internships to be exempted from the operation of labour standards, with the general exception of health and safety requirements. ${ }^{62}$

Regulation and policy responses should, ideally, look first to ensure that the focus in any period of work experience is on developing workplace-specific skills and, secondly, to ensure that financial considerations and existing networks are not a barrier to young people from less advantaged backgrounds accessing high-quality placements. Notwithstanding the efforts of the European Union to impose quality standards, ${ }^{63}$ few countries can claim to have taken decisive action in this regard. However, the approach adopted in France arguably provides a useful model. In addition to requiring a tripartite arrangement with an educational institution, the Education Code requires effective supervision by both the institution and the host organization, limits working hours, and mandates remuneration for placements lasting more than two months. ${ }^{64}$ Together with government-led policies, strengthened regulation of this type should in principle help to promote fairness in access to work experience by students from across the socio-economic spectrum, and work towards eliminating the worst of the exploitative organizational practices.

Universities are also key demand-side stakeholders in this debate and have demonstrated a strong commitment to educationally focused work experience. Higher education institutions have adopted an increasing array of WIL pedagogies in order to strengthen their academic courses, improve employability for students and, ultimately, signal that they deliver a return on investment. ${ }^{65}$ Convincing evidence for enhanced employment outcomes remains thin, yet we cannot ignore that formal, educationally focused WIL is consistently perceived by educators, students and employers as a legitimate pedagogy that results in positive benefits for critical thinking skills, improved knowledge related to an area of study and valuable exposure to professional practice. ${ }^{66}$ Roberts sug-

62 Ibid.

63 European Commission, 'Applying the Quality Framework for Traineeships' (2016) European Commission Staff Working Document COM(2016) 646 final.

64 Anne Hewitt, 'Avoiding the Trap of Exploitative Work: A National Approach to Making Work-Integrated Learning Effective, Equitable and Safe' (2018) 31 Aust J Labour L 101.

65 Universities Australia, Work Integrated Learning in Australian Universities: Final Report (Universities Australia 2019).

66 Belinda McLennan and Shay Keating, 'Work-Integrated Learning (WIL) in Australian Universities: The Challenges of Mainstreaming WIL' (Career Development 
gested a number of recommendations for higher education institutions, including offering small wage subsidies for small- and medium-sized enterprises where the placement is not part of an accredited course, banning placements lasting for more than four weeks, and providing a matching service to ensure high-quality placements are available to disadvantaged students. ${ }^{67}$

\subsection{CONCLUSIONS}

We have examined two related assumptions supporting the proliferation of unpaid work experience: first, that it is possible to acquire a competitive advantage over peers in the labour market by participating and, secondly, that those who have an opportunity to participate do achieve enhanced employability and employment outcomes. We have shown that, as unpaid work experience becomes a central dimension of tertiary study, previous differentiation benefits from the practice are potentially erased. Further, although there is mixed evidence on employment outcomes, high-quality experiences appear to improve employment outcomes more than low-quality placements do. Since access to high-quality work experience is influenced by social background, policy and regulatory intervention is required to address the challenges this creates for intergenerational advantage and disadvantage. Whatever the rights or wrongs of these various debates, two issues demand further attention. One is the need for more research into the economic and social impacts of work experience arrangements, which have, by any measure, become a significant aspect of the transition from education to paid work for young people. The other is the need to closely interrogate assumptions about the relationship between work experience and employment, and about why, how and at what (or whose) cost it should be enhanced.

Learning - Maximising the Contribution of Work Integrated Learning to the Student Experienced NAGCAS Symposium, Melbourne, June 2008); Kramer and Usher (n 10).

${ }_{67}$ Roberts (n 4). 